\title{
Cultivar, Flower Stage, Silver Thiosulfate, and BA Interactions Affect Performance of Potted Miniature Roses
}

\author{
Lisa Chen Cushman' and H. Brent Pemberton ${ }^{2}$ \\ Texas A\&M University Agricultural Research and Extension Center, P. O. Box \\ E, Overton, TX 75684
}

\author{
John W. Kelly ${ }^{3}$ \\ Department of Horticulture, Clemson University, Clemson, SC 29634-0375
}

Additional index words. flower longevity, flower quality, flower development, plant growth regulator, simulated shipping, Rosa

\begin{abstract}
Experiments were conducted to study the interaction of cultivar, flower stage, silver thiosulfate (STS), and BA on flower senescence and leaf abscission in greenhousegrown potted miniature roses. Plants of Rosa L. 'Meijikatar' (Orange Sunblaze) and 'Meirutral' (Red Sunblaze) were sprayed with several concentrations of STS and BA in factorial combination. In winter, plants were sprayed with STS at 0 or $2 \mathrm{~mm}$ and BA at 0 , $0.02,0.04,0.11,0.22$, or $0.44 \mathrm{~mm}$ In spring, flowers at three stages of development were sprayed with STS at 0,2 , or $3 \mathrm{~mm}$, and BA at $0,0.02,0.04,0.22$, or $0.44 \mathrm{~mm}$ One day after treatment in both experiments, plants were placed in darkness at $16 \mathrm{C}$ for 4 days to simulate shipping, and then they were evaluated in a controlled environment at 21C. Poststorage floral longevity (PSFL) was longer for 'Meirutral' than for 'Meijikatar' plants, regardless of chemical treatment or flower stage. Flowers that were in the bud stage (stage 1) before simulated shipping lasted longer than flowers showing color (stages 2 and 3), regardless of cultivar or chemical treatment. Combinations of STS and BA did not increase PSFL compared to STS alone. Plants treated with 2 or 3 mMSTS exhibited longer PSFL than nontreated plants; however, 2 and 3 mm were about equally effective. STS at 4 mm was phytotoxic in a preliminary experiment. Applying BA alone did not affect PSFL, but did improve postharvest flower opening on 'Meijikatar' plants about the same as STS applied alone. The large flowering cultivars represented by 'Meijikatar' and 'Meirutral' appear to be nonresponsive to BA. A star-shaped malformation was induced on 'Meijikatar' and 'Meirutral' plants by simulated shipping and was not prevented by STS or BA. Chemical name used: $\mathrm{N}$-(phenylmethyl) -1H-purin-6-amine (BA).
\end{abstract}

Simulated shipping of 'Pink Margo Koster', 'Orange Margo Koster', and 'Red Garnette' potted rose plants at 20 to $22 \mathrm{C}$ increased flower and leaf abscission compared to shipping at 1 to 3C (Halevy and Kofranek, 1976). This response also has been found on newer miniature, pot-forcing rose cultivars (Chen, 1990) and represents a serious limitation to their successful use as a floricultural crop (Clark et al., 1991).

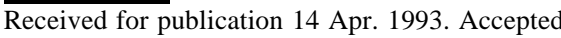
for publication 27 Jan. 1994. Texas Agricultural Expt. Station manuscript no. TA31119. We acknowledge Conard-Pyle Co., West Grove, Pa., and Yoder Brother's, Barberton, Ohio, for supplying miniature rose plants and Charles E. Gates, Dept. of Statistics, Texas A\&M Univ., College Station, for statistical consulting. This research was funded in part by a grant from the American Florist Endowment, Chicago. The cost of publishing this paper was defrayed in part by the payment of page charges, Under postal regulations, this paper therefore must be hereby marked advertisement solely to indicate this fact.

${ }^{1}$ Former Graduate Student. Current address: Agracetus, 8520 University Green, Middleton, WI 53562 .

${ }^{2}$ Associate Professor.

${ }^{3}$ Professor and Department Head.
BA, a synthetic cytokinin, reduces leaf chlorosis on 'Meijikatar' potted rose plants stored 5 days at 16C (Clark et al., 1991) and prolongs flower longevity of the short-lived, cut 'Golden Wave' rose (Mayak and Halevy, 1970). Silver thiosulfate (STS) prolonged flower longevity in cut Dianthus (Mor,1981), cut Lathyrus (Mor et al., 1984), Zygocactus potted plants (Cameron and Reid, 1981), and cut Rosa (Faragher et al., 1987). Also, Hibiscus rosa-sinensis L. flower buds treated with STS exhibited less injury after storage in darkness than nontreated buds (Hoyer, 1986; Thaxton et al., 1988). Sytsema (1986) reported that a combination of BA and STS prolonged flower longevity and improved flower development and bud opening of cut Freesia. STS and BA have been reported to prolong the longevity of potted Rosa hybrida 'Victory Parade' when each was applied alone (Serek, 1993; Serek and Andersen, 1993). However, we were unable to find reports on cytokinin and STS combination treatments for extending potted rose longevity.

Serek and Andersen (1993) separated the postharvest response of flowers to chemical treatments into those that opened in the greenhouse vs. those that opened in the interior evaluation environment, but did not define the floral stages of development at the time of treatment. Although Clark et al. (1991) measured the effect of BA on leaf abscission of several potted rose cultivars, the response of the flowers was not reported. Our objective was to report the effects of BA and STS application (alone and in combination) on two cultivars of greenhouse-grown, potted, miniature rose flowers at defined stages of development held at high temperature during simulated shipping.

\section{Materials and Methods}

Winter protocol. Dormant plants of 'Meijikatar' and 'Meirutral' were received from the Conard-Pyle Co., West Grove, Pa., on 14 Dec. 1988. The plants $(10-15 \mathrm{~cm}$ tall) were shipped in 550-ml pots, immediately pruned to 5 to $8 \mathrm{~cm}$ tall, and then forced in a glasshouse (21C day/15C night) under natural light. Osmocote 14N-6.2P-11.6K (GraceSierra Horticultural Products Co., Milpitas, Calif.) was surface-applied at $1.5 \mathrm{~g} / \mathrm{pot}$, and a two-feed and one-leach water schedule with 200 ppm N from Peter's 20N-8.9P-16.6K (Grace-Sierra Horticultural Products Co., Fogelsville, $\mathrm{Pa}$.) was followed throughout production.

On 8 Feb. 1989, 1 day before simulated shipping, plants that had at least one flower at stage 3 (Table 1) were sprayed to runoff with STS and BA in factorial combination. Solutions were prepared on the day of application. STS solutions were prepared according to Reid et al. (1980). Wetting agent Multispread90 (Schall Chemical, Monte Vista, Colo.) was used for all solutions. Each plant was sprayed with $17 \mathrm{ml}$ of 0 or $2 \mathrm{mmSTS}$, which resulted in 0 or $3.7 \mathrm{mg} \mathrm{Ag}$ per plant, respectively. After drying, the plants were sprayed subsequently with $14 \mathrm{ml}$ of $0,0.02,0.04,0.11,0.22$, or 0.44 $\mathrm{mM}$ BA solutions, resulting in $0,0.07,0.14$, $0.35,0.7$, or $1.4 \mathrm{mg}$ BA per plant, respectively. The nontreated plants were sprayed with water containing the wetting agent. On the day of storage, five flowers at stage 2 were labeled at random on the five plants used for each treatment. After all plants were watered well and the leaves were dry, the plants were placed in paper sleeves $10 \mathrm{~cm}$ in diameter and placed randomly into $27 \times 47 \times 41-\mathrm{cm}$ cardboard boxes. Holes $5 \mathrm{~cm}$ in diameter were cut at a height of $30 \mathrm{~cm}$ on the box sides for ventilation. Based on earlier experiments to determine shipping disorders with potted roses (Chen, 1990), the boxes were placed in an

Table 1. Flower development stages of miniature roses.

\begin{tabular}{ll}
\hline Flower stage & \multicolumn{1}{c}{ Description } \\
\hline 1 & Tight bud. calyx reflexing \\
2 & $\begin{array}{l}\text { Showing color, calyx reflexing, } \\
\text { no petals reflexed }\end{array}$ \\
3 & $\begin{array}{l}\text { Full color, petals beginning to } \\
\text { reflex, traditional bud stage }\end{array}$ \\
4 & Several petals reflexed, traditional \\
& exhibition stage \\
5 & Full open \\
6 & Postharvest life over, petal wilting or \\
& abscission \\
\hline
\end{tabular}


unlit, well-ventilated, controlled-temperature room at $16 \pm 1 \mathrm{C}$ for 4 days to simulate shipping. After storage, plants were randomly placed in a continuously lit simulated interior evaluation room at $21 \pm 1 \mathrm{C}$ under $30 \mu \mathrm{mol} \cdot \mathrm{m}^{-2} \cdot \mathrm{s}^{-1}$ photosynthetic photon flux from cool-white fluorescent lamps. Plants were also left in the glasshouse during the shipping and evaluation phases for observation. All plants were watered as needed during the evaluation phase.

Each labeled flower was evaluated daily for flower longevity and quality. Postharvest life ended when the flower abscised or when it reached stage 6 . Poststorage floral longevity (PSFL) was the period between the end of storage and the day postharvest life ended. Flower quality was rated 1,2 , or 3 ( $1=$ the best and $3=$ the worst). Flowers that developed normally, opened fully with good form, and then remained on the plant until petals wilted and abscised (stage 6) were rated 1. Flowers that developed to stage 6 but exhibited deviations from good form or color at stage 5 or before were characterized as 2 . Flowers that either abscised without opening, never fully opened before petal wilting and abscission, or exhibited severe color or form deviations were rated 3. Plants left in the greenhouse were used as a reference for normal flower development. Leaf abscission was monitored during the interior phase and rated on a scale of 1 to $10: 1$ $=0 \%$ to $10 \%$ abscission and $10=91 \%$ to $100 \%$ abscission on day 7. If leaf yellowing occurred, yellow leaves were included with the abscised leaves in assigning a rating.

Spring protocol. Cultural practices, spray method, storage procedure, and postharvest evaluation were about the same as for the winter experiment; however, there were some differences. Actively growing 'Meijikatar' and 'Meirutral' liners in 232-ml pots were received from Yoder Brother's, Fort Meyers, Fla., on 23 Mar. and 12 Apr. 1989, respectively. Liners were transplanted into 550-ml pots using Fafard Mix no. 3 (Fafard, Anderson, S.C.) potting medium and then placed in a glasshouse covered with $30 \%$ Saran shade at a $24 \mathrm{C}$ day/18C night cycle. When roots were visible at the bottom of the pot, shoots were pruned to 5 to $8 \mathrm{~cm}$ to begin the final forcing period. BA treatment at $0.11 \mathrm{~mm}$ was omitted, but STS at $3 \mathrm{~mm}$ (5.5 mg Ag per plant) was added. Surf Aid $(0.1 \%)$ (Riverside/Terra Corp., Sioux City, Iowa) was used as a wetting agent. Two additional control treatments were added to include nontreated plants placed in the interior and glasshouse on the same day simulated shipping began. Simulated shipping started 28 May for 'Meijikataf and 16 June for 'Meirutral'. Flowers at stages 1,2, or 3 (Table 1) were labeled at the start of storage. Highest stage of flower development reached during the evaluation period (flower opening) was also determined.

Statistics. Poststorage floral longevity means were correlated with the standard deviation so that data were transformed using the natural log before analysis (Steel and Tome, 1980). The analysis of variance assumptions were checked (Little, 1985) for the rating data and no transformations were necessary.
For the winter experiment, a completely randomized design with five replications was used. For the spring experiment, a completely randomized design with five replications for flower data and six replications for leaf abscission was used. The two additional nonsprayed, nonstored, control treatments in the spring experiment were not part of the factorial. The inclusion of labeled flower stages (FST) as a factor in the spring experiment required a split-plot design. The effects in the main plot involved the factors BA, STS, and cultivar (cv), with the effects involving FST as the subplots. Each FST level was to be chosen on each plant to ensure independence of the measurements, but all stages could not be found on each plant. As each FST level was labeled at random on all the plants in a treatment, the data for each treatment were averaged before analysis. This procedure made it necessary to use the interaction BA $\times$ STS $\times \mathrm{cv}$ as Error A and the interaction BA $\times$ STS $\times$ FST $\times \mathrm{cv}$ as Error B. When Error A was tested for significance with Error B and the $P$ value was $>0.25$, the two error terms were pooled and used for testing the significance of all the effects (Bancroft, 1964). Leaf abscission data were analyzed using the same methods as described for the flower data, except that no flower stage factor was involved.

\section{Results and Discussion}

Winter experiment. BA treatment had no effect on any of the variables measured. However, 2 mM STS increased PSFL by 5.9 days regardless of cultivar or BA treatment (Table 2). In addition, 'Meirutral' flowers lasted 3.1 days longer than 'Meijikatar' flowers, regardless of treatment. STS had no practical effect on the flower quality rating (overall average 2.9 ), with ratings $>1.5$ for both cultivars. An average flower quality rating $>1.5$ was considered commercially unacceptable. Flower abscission and abnormal flower color or form were the reasons for the poor flower quality. Petal blueing and a star-shaped malformation were observed on 'Meijikatar' flowers. For 'Meirutral' flowers, petal blackening was observed in addition to the blueing and malformation (Fig. 1). Leaf abscission was absent during the evaluation period (data not shown).

Spring experiment. As in the winter experiment, BA did not affect PSFL (data not shown), but 2 and 3 mM STS increased PSFL by 4.3 and 4.5 days, respectively (Table 3 ), regardless of BA, labeled flower stage, or cultivar. When the four storage days were added to PSFL, flowers on the nontreated but stored control plants for both cultivars exhibited a longevity $(11.6+4=15.6$ days $)$ similar to the flowers on the nonstored, nonsprayed, control plants ( 16.1 days). Storage at $16 \mathrm{C}$ for 4 days, therefore, had little effect on PSFL, as was also reported by Chen (1990). 'Meirutral' flowers lasted 5.5 days longer than 'Meijikatar' flowers (Table 3 ). As expected, stage 1 flowers lasted longer than stage 2 or 3 flowers regardless of chemical treatment or cultivar (Table 3). Leaf abscission was minimal (data not shown).

The overall flower quality rating was 2.2
Table 2. Effect of BA, silver thiosulfate (STS), and cultivar (cv) on poststorage floral longevity (PSFL) of potted roses (Writer 1988-89). Data were transformed using natural log before analysis, means on original scale.

\begin{tabular}{lc}
\hline Variable & PSFL (days) \\
\hline STS (rnM) & $7.9 \mathrm{~B}^{2}$ \\
0 & $13.8 \mathrm{~A}$ \\
2 & \\
Cultivar & $9.3 \mathrm{~B}$ \\
Meijikatm & $12.4 \mathrm{~A}$ \\
Meirutral & \\
& $\underline{\text { F values }}$ \\
Significance & $2.04^{\mathrm{Ns}}$ \\
BA & $147.87^{* *}$ \\
STS & $1.74^{\mathrm{NS}}$ \\
BA $\times$ STS & $40.68^{* *}$ \\
cv & $1.51^{\mathrm{Ns}}$ \\
BA $\times$ cv & $1.67^{\mathrm{Ns}}$ \\
STS $\times$ cv & $0.51^{\mathrm{Ns}}$ \\
BA $\times$ STS $\times$ cv & 0.07 \\
Mean square error & \\
\hline Mean separation betwen STS levels & or $6 \mathrm{ween}$
\end{tabular}

${ }^{2}$ Mean separation between STS levels or between cultivars by $\mathrm{F}$ test at $P \leq 0.01$.

${ }^{\text {NS,** }}$ Nonsignificant or significant at $P \leq 0.01$, respectively.

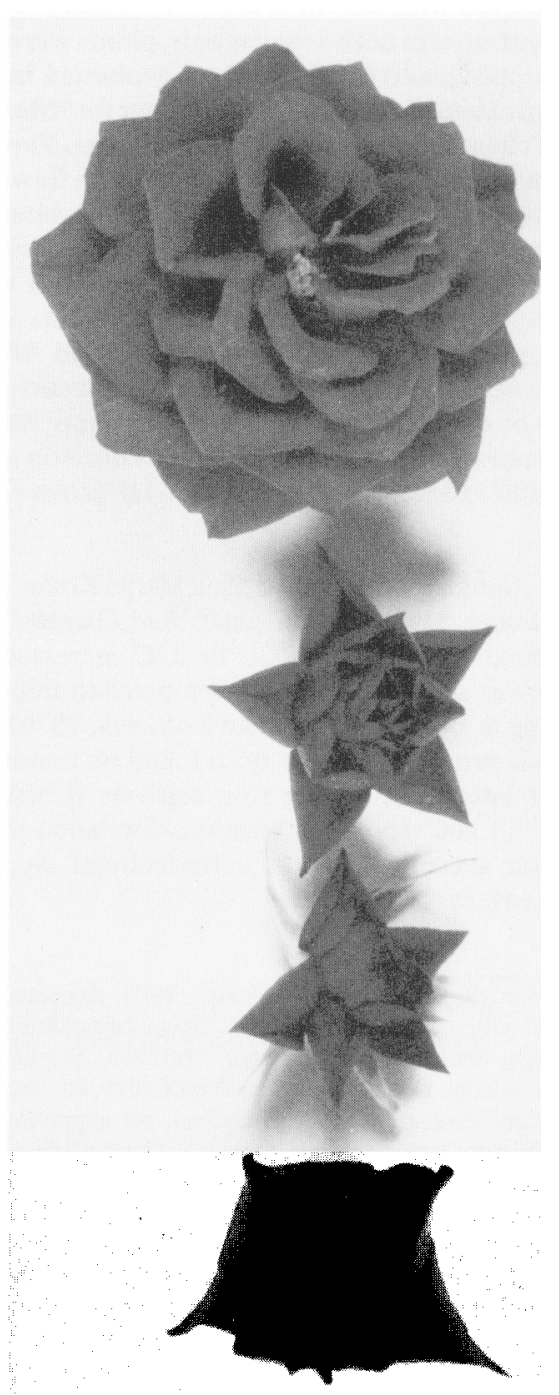

Fig. 1. Flowers from 'Meirutral' miniature potted rose plants. (top) Flower is normal. (bottom) Note the star-shape of the abnormal flowers. 
for all plants in the spring experiment and was $>1.5$, the rating deemed by us to be the upper limit for commercial acceptability. Flower quality was rated 1.0 and 1.3 for the nonsprayed, nonstored, glasshouse and interior control plants, respectively. Therefore, simulated shipping at $16 \mathrm{C}$ for 4 days resulted in inferior flower quality, regardless of treatment applied.

For 'Meijikatar' plants, the flower stage did not affect the highest stage of flower development reached during the evaluation period, regardless" of chemical treatment (Table 4). For 'Meirutral' plants, stage 1 flowers opened better than stage 3 flowers. When BA alone was applied, flower opening improved by as much as 1.1 stages to 4.5 for 'Meijikatar', but not for 'Meirutral', which exhibited an average flower development stage of 4.5 (data not shown). STS alone at either 2 or $3 \mathrm{~mm} \mathrm{im-}$ proved flower opening from 3.4. to 5.0 for 'Meijikatar' but did not have a significant effect on 'Meirutral' flowers.

Our results show no benefit to applying BA on potted rose flower longevity and quality. This finding contrasts with Halevy and Kofranek's (1976) report that showed a decrease in flower abscission on 'Pink Margo

Table 3. Effect of BA, silver thiosulfate (STS), cultivar (cv), and flower stage (FST) on poststorage floral longevity (PSFL) of potted roses (Spring 1989), Data were transformed using natural $\log$ before analysis (means on original scale).

\begin{tabular}{|c|c|}
\hline Variable & PSFL (days) \\
\hline \multicolumn{2}{|l|}{$\overline{\text { STS (mM) }}$} \\
\hline 0 & 12.7 \\
\hline 2 & 17.0 \\
\hline 3 & 17.2 \\
\hline \multicolumn{2}{|l|}{ Cultivar } \\
\hline Meijikatar & $12.9 \mathrm{~B}^{x}$ \\
\hline Meirutral & $18.4 \mathrm{~A}$ \\
\hline \multicolumn{2}{|l|}{ Flower stage } \\
\hline 1 & $19.0 \mathrm{~A}$ \\
\hline 2 & $14.4 \mathrm{~B}$ \\
\hline 3 & $13.5 \mathrm{~B}$ \\
\hline Significance & F values \\
\hline BA & $0.31^{\mathrm{Ns}}$ \\
\hline STS & $28.95^{* *}$ \\
\hline STS linear & $52.47^{* *}$ \\
\hline STS quadratic & $5.43^{*}$ \\
\hline BA $\times$ STS & $1.38^{\mathrm{Ns}}$ \\
\hline $\mathrm{cv}$ & $94.10^{* *}$ \\
\hline $\mathrm{BA} \times \mathrm{cV}$ & $0.50^{\mathrm{Ns}}$ \\
\hline $\mathrm{STS} \times \mathrm{cv}$ & $0.12^{\mathrm{Ns}}$ \\
\hline \multicolumn{2}{|l|}{ Mean square Error A } \\
\hline $\begin{array}{c}(\mathrm{BA} \times \mathrm{STS} \times \mathrm{cv}) \\
\mathrm{BA} \times \mathrm{STS} \times \mathrm{cv}\end{array}$ & $\begin{array}{l}0.03483 \\
2.55^{\mathrm{Ns}}\end{array}$ \\
\hline FST & $67.32^{* *}$ \\
\hline $\mathrm{BA} \times \mathrm{FST}$ & $1.52^{\mathrm{Ns}}$ \\
\hline $\mathrm{STS} \times \mathrm{FST}$ & $1.26^{\mathrm{Ns}}$ \\
\hline $\mathrm{BA} \times \mathrm{STS} \times \mathrm{FST}$ & $0.94^{\mathrm{Ns}}$ \\
\hline FST $\times \mathrm{cv}$ & $2.75^{\mathrm{Ns}}$ \\
\hline $\mathrm{STS} \times \mathrm{FST} \times \mathrm{cv}$ & $2.45^{\mathrm{Ns}}$ \\
\hline $\mathrm{BS} \times \mathrm{FST} \times \mathrm{cv}$ & $0.72^{\mathrm{ss}}$ \\
\hline Mean square Error B & \\
\hline$(\mathrm{BA} \times \mathrm{STS} \times \mathrm{FST} \times \mathrm{cv})$ & 0.01364 \\
\hline
\end{tabular}

${ }^{3}$ Mean separation between cultivars or between flower stages by Duncan's multiple range test at $\mathrm{P} \leq$ 0.01 .

Ns,$*$,**Nonsignificant or significant at $\mathrm{P} \leq 0.05$ or 0.01 , respectively.
Koster' plants in response to 6-(benzylamino)9-(2-tetrahydropyranyl) -9H-purine (PBA) and with Serek and Andersen's report (1993) that showed an increase in 'Victory Parade' flower longevity in response to BA. For many rose cultivars, adding BA to a vase solution was not effective for lengthening cut-flower vase life (Mor and Zieslin, 1987). Also, flowers of 'Lovita', a long-lived rose cultivar, were less responsive to exogenous application of BA than those of 'Golden Wave', a short-lived rose cultivar (Mayak and Halevy, 1970). In our experiment, 'Meirutral' was a long-lived potted rose cultivar compared to 'Meijikatar' because of the longer PSFL, regardless of treatment. Therefore, BA had an effect on the relatively short-lived 'Meijikatar', although it only affected flower opening. In addition, miniature potted rose cultivars are separated into two categories: large flowering cultivars represented by 'Meijikatar' and 'Meirutral' appear to be nonresponsive to BA, whereas small flowering cultivars represented by 'Victory Parade' appear to be responsive to BA (Serek and Andersen, 1993).

Halevy and Kofranek ( 1976) reported that the cytokinin PBA prevents flower abscission in 'Pink Margo Koster' potted rose, and because of its greater mobility in plants (Weaver, 1972), it may be more effective than BA in abscission prevention. BA was better for preventing leaf abscission in potted rose plants among several cytokinins examined (Clark et al., 1991), and that is why we used it.

STS increased floral longevity on 'Meijikatar' and 'Meirutral' plants and improved flower opening on 'Meijikatar' plants. Serek (1993) showed that potted roses are sensitive to ethylene and that STS increased flower longevity by preventing abscission. However, flower longevity decreased and abscission increased on 'Victory Parade' plants as the STS concentration increased from 0.4 to $1.6 \mathrm{~mm}$ (Serek, 1993). PSFL was the same for 2 or 3 mm STS on 'Meijikatar' and 'Meirutral' plants (Table 3). Plants of large flowering cultivars such as 'Meijikatar' and 'Meirutral' are likely more STS tolerant than plants of small flowering cultivars such as 'Victory Parade'. Phytotoxicity was absent in Serek's (1993) and our experiments. The chemical treatments did not cause the malformation observed (Fig. 1); however, a spray application of 4 mM STS resulted in foliar damage on 'Meirutral' plants in a preliminary experiment (unpublished).

Reid et al. ( 1989) reported that, depending on the cultivar, ethylene caused cut rose flowers to open improperly, prevented opening altogether, induced petals and leaves to abscise, or caused a star-shaped flower abnormality during opening. The star-shaped malformation reported on cut roses by Reid et al. (1989) was also observed as a response to high-temperature shipping of 'Meijikatar' and 'Meirutral' plants in our study (Fig. 1). Because the plants were not treated with ethylene, this malformation is most likely a result of endogenously produced ethylene induced by the simulated shipping treatment, This effect was not prevented by STS or BA treatment.
Flowers that were in the bud stage (stage 1) before simulated shipping lasted longer than flowers showing color, regardless of cultivar. Also, stage 1 flowers opened better than those at stage 2 or 3 on 'Meirutral' plants. This result is in contrast to those of Serek and Andersen (1993) with 'Victory Parade', where flowers that had started to open before simulated shipping (corresponding to our stage 3 ) opened better than those opening after simulated shipping (corresponding to our stages 1 and 2). The lower light intensity used in their experiment for the postshipping interior evaluation phase may explain the difference, or 'Victory Parade' flowers might be more sensitive to the low-light conditions encountered in interior environments. Nell and Noordegraaf (1991) found a cultivar-dependent response to light intensity in the postharvest interior evaluation environment.

Despite the improvement in floral longevity of potted miniature roses, flower blueing and blackening was still a problem that was not prevented by STS treatment. Further work is needed with STS applications at shipping temperature and duration combinations that we did not test. Low shipping temperatures have been shown to maintain plant quality better than higher ones for the new potted forcing cultivars (Chen, 1990; Nell and Noordegraaf, 1992) and for those traditionally used (Halevy and Kofranek, 1976). The use of

Table 4. Effect of BA, silver thiosulfate (STS), cultivar (cv), and flower stage (FST) on highest stage of flower development reached during the evaluation period of potted roses (Spring 1989).

\begin{tabular}{lcc}
\hline \hline Cultivar & FST & $\begin{array}{c}\text { Highest flower } \\
\text { development stage }\end{array}$ \\
\hline Meijikatar & 1 & $4.5 \mathrm{a}^{\mathrm{z}}$ \\
& 2 & $4.4 \mathrm{a}$ \\
Meirutral & 3 & $4.8 \mathrm{a}$ \\
& 1 & $4.7 \mathrm{a}$ \\
& 2 & $4.5 \mathrm{ab}$ \\
& 3 & $4.4 \mathrm{~b}$
\end{tabular}

\begin{tabular}{|c|c|}
\hline Significance & F values \\
\hline BA & $0.70^{\text {Ns }}$ \\
\hline STS & $10.93^{* *}$ \\
\hline $\mathrm{BA} \times \mathrm{STS}$ & $0.95^{\mathrm{ss}}$ \\
\hline $\mathrm{cv}$ & $0.00^{\mathrm{Ns}}$ \\
\hline $\mathrm{BA} \times \mathrm{cv}$ & $0.54^{\mathrm{Ns}}$ \\
\hline STS $\times \mathrm{cv}$ & $0.13^{\text {Ns }}$ \\
\hline $\begin{array}{c}\text { Mean square Error A } \\
(\mathrm{BA} \times \mathrm{STS} \times \mathrm{cv})\end{array}$ & 0.2698 \\
\hline Meijikatar & \\
\hline BA linear $\times$ STS linear & $5.85^{*}$ \\
\hline All other effects & NS \\
\hline Meirutral & \\
\hline All effects & NS \\
\hline FST & $4.55^{*}$ \\
\hline $\mathrm{BA} \times \mathrm{FST}$ & $2.43^{\mathrm{Ns}}$ \\
\hline $\mathrm{STS} \times \mathrm{FST}$ & $2.76^{\mathrm{Ns}}$ \\
\hline $\mathrm{BA} \times \mathrm{STS} \times \mathrm{FST}$ & $0.73^{\mathrm{Ns}}$ \\
\hline $\mathrm{FST} \times \mathrm{cv}$ & $10.56^{* *}$ \\
\hline $\mathrm{STS} \times \mathrm{FST} \times \mathrm{cv}$ & $2.34^{\mathrm{Ns}}$ \\
\hline $\mathrm{BA} \times \mathrm{FST} \times \mathrm{cv}$ & $1.21^{\mathrm{Ns}}$ \\
\hline Mean square Error B & \\
\hline$(\mathrm{BA} \times \mathrm{STS} \times \mathrm{FST} \times \mathrm{cv})$ & 0.06851 \\
\hline
\end{tabular}

${ }^{2}$ Mean separation within cultivar by Duncan's multiple range test at $P \leq 0.05$,

Ns $, *, * *$ Nonsignificant or significant at $P \leq 0.05$ or 0.01 , respectively. 
STS sprays before shipping could further enhance the benefit of lower shipping temperatures.

\section{Literature Cited}

Bancroft, T.A. 1964. Analysis and inference for incompletely specified models involving the use of preliminary test(s) of significance. Biometrics 20:427-447.

Cameron, A.C. and M.S. Reid. 1981. The use of silver thiosulfate anionic complex as a foliar spray to prevent flower abscission of Zygocactus. HortScience 16:761-762.

Chen, L.L. 1990. Growth regulator reversal of simulated high temperature shipping effects on flower senescence and leaf abscission in miniature potted rose plants. MS Thesis, Texas A\&M Univ., College Station.

Clark, D. G., J.W, Kelly, and H.B. Pemberton. 1991. Postharvest quality characteristics of cultivars of potted rose in response to holding conditions and cytokinins, HortScience 26:1195-1197.

Faragher, J. D., Y. Mor, and F. Johnson. 1987. Role of amino-cyclopropane-1-carboxylic acid (ACC) in control of ethylene production in fresh and cold-stored rose flowers. J. Expt. Bet. 38: 18391847 ,

Halevy, A.H. and A.M. Kofranek. 1976. The pre- vention of flower bud and leaf abscission in pot roses during simulated transport, J. Amer. Soc. Hort. Sci. 101:658-660.

Hoyer, L. 1986. Silver thiosulfate canto some extent prevent leaf, bud and flower drop in Hibiscus rosa-sinensis caused by ethylene and darkness. Acta Hort. 181:147-153.

Little, T.M. 1985. Analysis of percentage and rating scale data. HortScience 20:642-644.

Mayak, S. and A.H. Halevy. 1970, Cytokinin activity in rose petals and its relation to senescence. Plant Physiol. 46:497-499.

Mor, Y. 1981. Effect of silver-thiosulfate pretreatment on vase life of cut standard carnations, spray carnations, and gladiolus, after a transcontinental truck shipment. HortScience 16:766768.

Mor, Y., M.S. Reid, and A.M. Kofranek. 1984 Pulse treatments with silver thiosulfate and sucrose improve the vase life of sweet peas. J. Amer. Soc. Hort. Sci. 109:866-868.

Mor, Y. and N. Zieslin. 1987. Plant growth regulators in rose plants. Hort. Rev. 9:53-73.

Nell, T.A. and C.V. Noordegraaf. 1991. Simulated transport, postproduction irradiance influence postproduction performance of potted roses. HortScience 26: 1401-1404.

Nell, T.A. and C.V. Noordegraaf. 1992. Postproduction performance of potted rose under simu- lated transport and low irradiance levels. HortScience 26:239-241.

Reid, M. S., R.Y. Evans, L.L. Dodge, and Y. Mor. 1989. Ethylene and silver thiosulfate influence opening of cut rose flowers. J. Amer. Soc. Hort Sci. 114:436-440.

Reid, M. S., J.L. Paul, M.B. Farhoomand, A.M Kofranek, and G.L. Staby. 1980. Pulse treatments with the silver thiosulfate complex extend the vase life of cut carnations. J. Amer. Soc. Hort. Sci. 105:25-27.

Serek, M. 1993. Ethephon and silver thiosulfate affect postharvest characteristics of Rosa hybrida 'Victory Parade'. HortScience 28:199-200.

Serek, M. and A.S. Andersen. 1993, AOA and BA influence on floral development and longevity of potted 'Victory Parade' miniature rose. HortScience 28: 1039-1040.

Steel, R.G.D. and J.H. Torrie. 1980. Principles and procedures of statistics, A biometrical approach. 2nd ed. McGraw-Hill, New York.

Sytsema, W. 1986. Post-harvest treatment of Freesia with silver thiosulfate and cytokinins, Acts Hort. 181:439-441.

Thaxton, D. R., J.W, Kelly, and J.J. Frett. 1988 , Control of Hibiscus rosa-sinensis L. bud abscission during shipping. Scientia Hort. 34:13 1-1 37.

Weaver, R.J. 1972. Plant growth substances in agriculture. W.H. Freeman and Co., San Francisco. 